Research Article

\title{
Antibacterial Screening of Mangrove Extract Library Showed Potential Activity against Escherichia coli and Staphylococcus aureus
}

\author{
Kholis Abdurachim Audah 1,2*, Razethy Batubara ${ }^{2}$, Julkipli ${ }^{2}$, Elza Wijaya ${ }^{2}$, Evi Kurniawaty ${ }^{3}$, \\ Irmanida Batubara ${ }^{4}$ \\ ${ }^{1}$ Directorate of Academic Research and Community Services, Swiss German University, Tangerang 15143, \\ Indonesia \\ ${ }^{2}$ Department of Biomedical Engineering, Faculty of Life Sciences and Technology, Swiss German University, \\ Tangerang 15143, Indonesia \\ ${ }^{3}$ Faculty of Medicine, University of Lampung, Lampung 35141, Indonesia \\ ${ }^{4}$ Tropical Biopharmaca Tropica Research Center, Department of Chemistry, Faculty of Mathematics and, Natural \\ Science, IPB University, Bogor 16680, Indonesia
}

Article history:

Submission October 2019

Revised December 2019

Accepted January 2019

*Corresponding author:

E-mail: audah@sgu.ac.id

\begin{abstract}
Humans are at a continuous battle against different types of diseases, so that extraordinary effort to accelerate drug discovery has become a necessity. Indonesian biodiversity is abundant natural resources that can be utilized as potential drug sources. Mangroves are among potential plant medicines that grow nearly at all Indonesian coastlines. The aim of this study was to evaluate the potential of mangrove extracts (extract library) as antibacterial agents. In this study, eight mangroves species with 16 samples from different parts of the plants such as leaf, bark or root were collected. Four types of solvents with different polarity, namely water, ethanol, ethyl acetate and hexane were used in maceration of samples producing 64 extracts. Disk diffusion method was used for antibacterial screening using five bacterial strains. There were 37 extracts showed antibacterial potential with the lowest and the highest inhibition indexes were 0.0283 and 1.8983 , respectively. The highest inhibition index was recorded for ethyl acetate extract of Bruguiera gymnorrhiza root (BgR (Ea)) against Escherichia coli. The second highest inhibition index was 0.7867 recorded water extract of Avicennia marina leaf (AmL (A)) against Staphylococcus aureus. Almost all of extract showed saponin and tannin in considerable amount. This supported the data that mangrove extracts were potential as antibacterial agents.
\end{abstract}

Keywords: Antimicrobial, drug discovery, drug resistant, extract library, Indonesian biodiversity

\section{Introduction}

Drug discovery is a lengthy and expensive process. On the other hand, different types of diseases or drug resistant pathogens are increasing in numbers from time to time. The World Health Organization once reported that as many as 30 new diseases could emerge in 20 years period of time [1]. Therefore, finding alternatives for drug sources is urgently required. Drug discovery through screening process utilizing natural products can become a solution of the slow and expensive drug discovery process using conventional way.

Indonesia is well known as one of world rich countries in biodiversity [2]. The country possesses approximately 14,000 islands, located between Indian and Pacific Oceans. According to Fauna and Flora International (FFI), Indonesia is home of approximately $11 \%$ or more than 30,000 of the world's flowering plants and other biota both in land and marine with significant figures [3].

One of potential plants as medicinal sources and widely spread along Indonesian coastline is mangrove that has potential as medicinal sources [4]. Along roughly 90,000-kilometer coastline, Indonesia is home of about 20 families with hundreds of species of mangroves and their associates

\section{How to cite:}

Audah KA, Batubara R, Julkipli et al. (2020) Species Identification, Phytochemical Constituents and Antibacterial Screening of Mangrove Extract Library. Journal of Tropical Life Science 10 (2): 105 - 111. doi: 10.11594/jtls.10.02.03 
or about $23 \%$ of total world mangrove forests [5].

Previous qualitative phytochemical studies showed that leaf extract of Rhizophora stylosa and Avicenna marina contains flavonoid, terpenoid, alkaloid, flavonoid and glycosidic phenolic [6]. Bioactivity of mangrove extracts against other types of diseases had also been reported [7]. The aim of this study was to evaluate the potential of mangrove extracts (extracts library) as antibacterial agents.

\section{Material and Methods \\ Plant materials}

Mangroves plants were collected from the Eastern Coastline of Lampung Province, Indonesia in May 2017. There were eight species of mangroves used in this study with the total of 16 samples collected from different parts of plants such as leaves, barks, and roots (Table 1). The eight species were identified for confirmation at the Herbarium of the Center for Biological Research of the Indonesian Institute of Sciences, Bogor, Indonesia. Species identification required at least two parts of each plant to be submitted to the Herbarium as shown in Figure 1.

\section{Sample preparations and extraction}

All samples were dried and ground to make powder. Water content analyses was performed according to the Association of Official Analytical Chemist (AOAC) [8]. The dried materials then extracted with maceration [9]. Four different solvents were used, which were $n$-hexane, ethyl acetate, ethanol and water. Ratio between solvent and dried material was $5: 1$ with overnight maceration, 3 : 1 with maceration for 17 and 7 hours. Extracts separated from their residues was concentrated with rotary evaporator. The yields were then determined based on the ratio of concentrated extract weight with initial sample weight. Extractions were performed triplicate.

\section{Antibacterial activity}

All bacterial strains used in this study (Escherichia coli, Staphylococcus aureus, Propionibacterium acnes, Pseudomonas mosselii, and Rhodococcus equi) were obtained from the Indonesia Culture Collection (InaCC). Disk diffusion method was used to determine antibacterial activity of mangrove extracts [10]. Media used for $E$. coli strain was Nutrient Agar (NA). Media used for S. aureus, P. acnes, P. mosselii, and R. equi
Table 1. Mangroves species and part of the plants used in this study*

\begin{tabular}{lcc}
\hline \multicolumn{1}{c}{ Name of Plants } & Part of Plants & Code \\
\hline Rhizophora apiculata & Leaf & RaL \\
& Bark & RaB \\
& Root & RaR \\
Bruguiera gymnorrhiza & Leaf & BgL \\
& Bark & BgB \\
& Root & BgR \\
Rhizophora mucronata & Leaf & RmL \\
& Bark & RmB \\
Thespesia populnea & Root & TpR \\
& Leaf & TpL \\
Avicennia marina & Fruit & TpF \\
\multirow{2}{*}{ Xylocarpus granatum } & Leaf & AmL \\
Ceriops tagal & Root & AmR \\
Sonneratia caseolaris & Leaf & XgL \\
\hline
\end{tabular}

Note: *Part of plants collected were based upon the nature of the plants. Sample codes were designated with capital and small letters indicating name of the species, followed by a capital letter indicating parts of the plant collected; L= leaf; $\mathrm{B}=$ =stem bark; $\mathrm{R}=$ root; $\mathrm{F}=$ fruit.

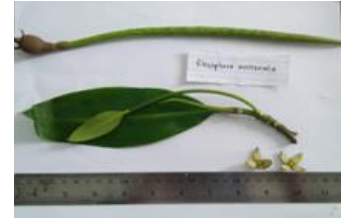

(a)

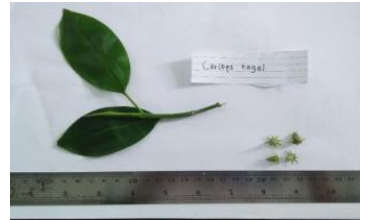

(c)

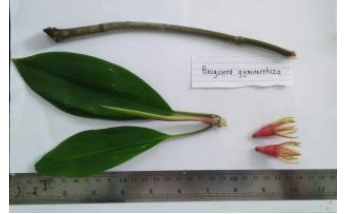

(e)

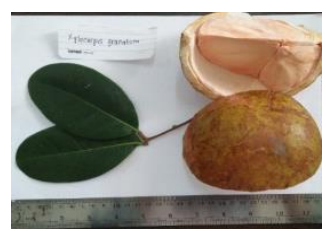

(g)

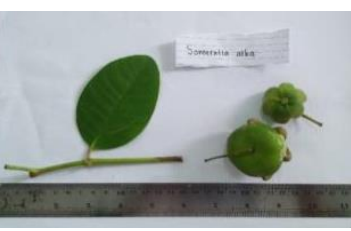

(b)

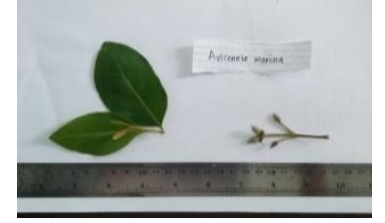

(d)

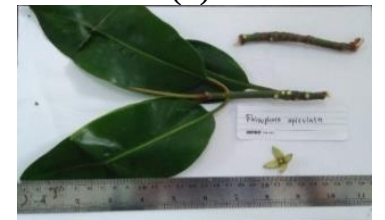

(f)
Figure 1. Species identification of mangrove plants: R. mucronata (a), S. alba (b), C. tagal (c), A. marina (d), B. gymnorhiza (e), R. apiculata (f), and X. moluccensis (g) 
strains were Tryptone Soya Agar (TSA). All bacterial strains were sub-cultured in Triptic Soy Broth (TSB) and incubated at $37^{\circ} \mathrm{C}$ overnight. Sterilized agar media was prepared. Bacterial suspension was mixed with the agar and solidified for 5 minutes. Disk paper with the size of $6 \mathrm{~mm}$ in diameter was placed on the solid agar media with tweezers and was dropped with $20 \mu \mathrm{L}$ of $1 \%$ extract in 20\% DMSO solvent. Tetracycline was used as positive control. Bacterial cultures were incubated at $37^{\circ} \mathrm{C}$ overnight. Inhibition zone diameter formed was measured in $\mathrm{mm}$ and performed in triplicates. Bacterial inhibition index value was calculated by using the following equation:

$$
\text { Inhibition index }=\frac{\emptyset \text { inhibition zone }-\emptyset \text { disk }}{\emptyset \text { disk }}
$$

\section{Qualitative phytochemical analysis}

Qualitative Phytochemical Analyses of plant samples were performed according to Harborne [11]. All reagents used in this study were obtained from Sigma-Aldrich. Alkaloids test was performed by mixing $4 \mathrm{~mL}$ of chloroform-ammonia mixture with $0.1 \mathrm{~g}$ crude extract and was then filtered. Few drops of $\mathrm{H}_{2} \mathrm{SO}_{4} 2 \mathrm{M}$ were added into the filtrate and mixed until two layers formed. Transparent layer (acidic layer) was divided into 3 reaction tubes. Mayer, Wagner, and Dragendorf reagents were added into each tube. Positive alkaloids test results indicated by the formation of white, brown or red precipitation by addition of Mayer, Wagner, or Dragendorf reagents, respectively.

Triterpenoid and steroid tests were performed by heating mixture of $0.1 \mathrm{~g}$ crude extract with 5 $\mathrm{ml}$ ethanol at $50^{\circ} \mathrm{C}$ and then filtered. The filtrate was then concentrated and dissolved with ether. The ether layer was dropped on a drop plate and air-dried. Few drops of Liebermann-Burchard reagent (concentrated $\mathrm{H}_{2} \mathrm{SO}_{4}$ and $\mathrm{CH}_{3} \mathrm{COOH}$ anhydrate) was added onto the drop plate. Positive triterpenoid test result indicated by the formation of red color and positive steroid test results indicated by the formation of green or blue color.

Phenolic and flavonoid tests were performed by mixing 0.1 gram of crude extract with $5 \mathrm{~mL}$ of distilled water and then boiled for 2 minutes and filtered. $\mathrm{NaOH} 10 \%$ was added into $2 \mathrm{~mL}$ of filtrate for phenolic test. Red color indicates that phe-
Table 2. Water content of simplicial*

\begin{tabular}{cccc}
\hline $\begin{array}{c}\text { Samples } \\
\text { code }\end{array}$ & $\begin{array}{c}\text { Water con- } \\
\text { tent (\%) }\end{array}$ & $\begin{array}{c}\text { Samples } \\
\text { code }\end{array}$ & $\begin{array}{c}\text { Water con- } \\
\text { tent (\%) }\end{array}$ \\
\hline RaL & 8.60 & TpR & 7.56 \\
RaB & 2.30 & TpL & 7.54 \\
RaR & 7.36 & TpF & 10.06 \\
BgL & 5.34 & AmL & 9.43 \\
BgB & 3.57 & AmR & 8.55 \\
BgR & 8.23 & XgL & 8.98 \\
RmL & 4.78 & CtL & 9.45 \\
RmB & 4.85 & ScL & 7.23 \\
\hline
\end{tabular}

*Water content of simplicial should be below $10 \%$ (suitable for analysis).

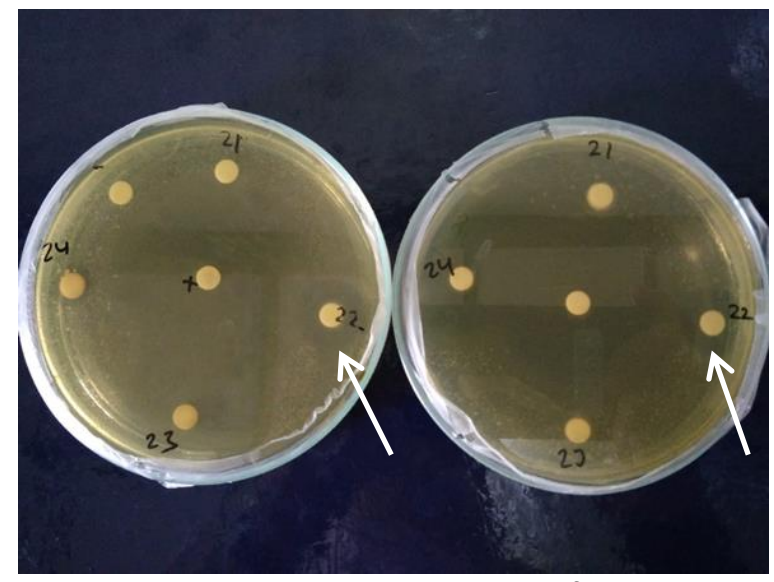

Figure 2. The largest inhibition zone formed due to the addition of extract of root of B. gymnorrhiza $(\mathrm{BgR}(\mathrm{Ea}))$ on agar media with gram negative bacteria $E$. coli with diameter 17.39 $\mathrm{mm}$ and inhibition index value of 1.8983 (as indicated by arrow). Bacterial culture was grown in duplicate.

nolic compounds are present in the sample. The presence of flavonoid compounds can be detected by mixing $0.1 \mathrm{~g}$ magnesium powder, $1 \mathrm{~mL}$ of concentrated $\mathrm{HCl}$ and $1 \mathrm{~mL}$ of amyl alcohol with 2 $\mathrm{mL}$ of the filtrated. The formations of red, yellow or orange color indicate a positive result.

Saponin and tannin tests were performed by mixing $0.1 \mathrm{~g}$ of crude extract with $5 \mathrm{~mL}$ distilled water and then boiled and filtered. Filtrate was divided into 2 reaction tubes. Saponin test was done by cooling the filtrated and mixed until foam formed. Positive result indicated by the formation of foam that lasts for about 10 minutes. Tannin test was done by mixing the filtrate with $\mathrm{FeCl}_{3} 10 \%$ solution. Positive result indicated by the formation of dark blue or blackish green color. 
Table 3. Yield of extracts (\%) *

\begin{tabular}{|c|c|c|c|c|c|c|c|}
\hline $\begin{array}{c}\text { Samples } \\
\text { code }\end{array}$ & Yield & $\begin{array}{c}\text { Samples } \\
\text { code }\end{array}$ & Yield & $\begin{array}{c}\text { Samples } \\
\text { code }\end{array}$ & Yield & $\begin{array}{c}\text { Samples } \\
\text { code }\end{array}$ & Yield \\
\hline $\mathrm{RaL}(\mathrm{H})$ & $1.28 \pm 0.38$ & BgB (H) & $0.26 \pm 0.02$ & $\mathrm{TpR}(\mathrm{H})$ & $0.14 \pm 0.04$ & $\operatorname{AmR}(\mathrm{H})$ & $0.50 \pm 0.07$ \\
\hline $\mathrm{RaL}(\mathrm{Ea})$ & $3.22 \pm 2.09$ & BgB (Ea) & $0.27 \pm 0.06$ & TpR (Ea) & $0.15 \pm 0.01$ & AmR (Ea) & $0.89 \pm 0.03$ \\
\hline $\mathrm{RaL}(\mathrm{Et})$ & $6.54 \pm 3.69$ & BgB (Et) & $2.30 \pm 0.09$ & TpR (Et) & $3.59 \pm 0.30$ & AmR (Et) & $1.98 \pm 0.02$ \\
\hline RaL (A) & $16.20 \pm 5.20$ & BgB (A) & $5.45 \pm 4.24$ & TpR (A) & $2.53 \pm 1.14$ & $\operatorname{AmR}(\mathrm{A})$ & $10.31 \pm 1.83$ \\
\hline $\mathrm{RaB}(\mathrm{H})$ & $0.42 \pm 0.20$ & $\operatorname{BgR}(\mathrm{H})$ & $0.29 \pm 0.05$ & TpL(H) & $2.46 \pm 0.34$ & XgL (H) & $0.76 \pm 0.08$ \\
\hline $\mathrm{RaB}(\mathrm{Ea})$ & $0.54 \pm 0.23$ & BgR (Ea) & $0.32 \pm 0.01$ & TpL (Ea) & $2.73 \pm 0.12$ & XgL (Ea) & $1.79 \pm 0.15$ \\
\hline $\mathrm{RaB}(\mathrm{Et})$ & $3.40 \pm 0.23$ & BgR (Et) & $8.95 \pm 0.32$ & TpL (Et) & $3.55 \pm 0.32$ & XgL (Et) & $6.94 \pm 0.76$ \\
\hline $\mathrm{RaB}(\mathrm{A})$ & $1.84 \pm 0.31$ & $\operatorname{BgR}(\mathrm{A})$ & $4.14 \pm 0.64$ & TpL (A) & $15.10 \pm 3.14$ & XgL (A) & $21.18 \pm 2.76$ \\
\hline $\operatorname{RaR}(\mathrm{H})$ & $0.25 \pm 0.03$ & $\mathrm{RmL}(\mathrm{H})$ & $1.04 \pm 0.13$ & $\mathrm{TpF}(\mathrm{H})$ & $3.08 \pm 0.79$ & CfL(H) & $2.41 \pm 0.03$ \\
\hline RaR (Ea) & $0.25 \pm 0.02$ & RmL (Ea) & $2.36 \pm 0.74$ & $\mathrm{TpF}(\mathrm{Ea})$ & $3.64 \pm 1.23$ & CfL (Ea) & $2.27 \pm 0.09$ \\
\hline $\mathrm{RaR}(\mathrm{Et})$ & $11.92 \pm 1.11$ & RmL (Et) & $2.49 \pm 0.51$ & $\mathrm{TpF}(\mathrm{Et})$ & $2.99 \pm 0.43$ & CfL (Et) & $10.86 \pm 1.00$ \\
\hline $\operatorname{RaR}(\mathrm{A})$ & $5.99 \pm 1.30$ & RmL (A) & $13.26 \pm 3.75$ & $\mathrm{TpF}(\mathrm{A})$ & $13.41 \pm 12.11$ & CfL (A) & $19.58 \pm 3.28$ \\
\hline BgL (H) & $2.6 \pm 0.71$ & $\mathrm{RmB}(\mathrm{H})$ & $0.26 \pm 0.04$ & $\operatorname{AmL}(\mathrm{H})$ & $1.7 \pm 0.45$ & ScL (H) & $1.52 \pm 0.25$ \\
\hline BgL (Ea) & $1.34 \pm 0.06$ & $\mathrm{RmB}(\mathrm{Ea})$ & $0.23 \pm 0.02$ & AmL (Ea) & $1.4 \pm 0.07$ & $\mathrm{ScL}(\mathrm{Ea})$ & $1.43 \pm 0.09$ \\
\hline $\mathrm{BgL}(\mathrm{Et})$ & $7.09 \pm 0.14$ & $\mathrm{RmB}(\mathrm{Et})$ & $4.88 \pm 2.38$ & AmL (Et) & $7.42 \pm 1.17$ & $\mathrm{ScL}(\mathrm{Et})$ & $9.46 \pm 0.10$ \\
\hline $\operatorname{BgL}(\mathrm{A})$ & $21.58 \pm 3.03$ & $\mathrm{RmB}(\mathrm{A})$ & $3.72 \pm 1.26$ & AmL (A) & $26.23 \pm 5.13$ & ScL (A) & $7.06 \pm 2.97$ \\
\hline
\end{tabular}

Note: *Solvents abbreviation in parenthesis; $\mathrm{H}=n$-hexane, $\mathrm{Ea}=$ ethyl acetate, $\mathrm{Et}=$ ethanol, $\mathrm{A}=$ water

\section{Results and Discussions Water content}

Water content of simplicial (Table 2) showed that 15 out of 16 samples were kept below $10 \%$ which is a suitable percentage for simplicial analysis according to Indonesian Herbal Pharmacopeia [8]. Only one sample with sample code 83 which was originated from fruit of Thespesia populnea showed a slightly higher water content than 10\% (10.06\%) (Table 2).

\section{Yield percentage}

The yield of extracts of the 16 samples were between $0.14 \%$ (highlighted in green) to $26.23 \%$ (highlighted yellow) that belonged to n-hexane extract of root of $R$. mucronata and water extract of leaf of A. marina, respectively as shown in Table 3. The data clearly showed that root extract using non polar solvent (n-hexane) resulted in lower yield percentage compared to more polar solvents (samples 74, 77, 81, and 85). This indicated that root sample contains less nonpolar constituents compared to other parts of plants.

\section{Antibacterial zone of inhibition}

Antibacterial screening of mangrove extracts in this study were targeted against gram positive bacteria represented by $S$. aureus, $P$. acnes and $R$. equi and against gram negative bacteria represented by P. mosselii dan E. coli. There were 37 out of 64 extracts that showed antibacterial activity as indicated by clear (inhibition) zone around the disk dropped with extract (Tabel 4). Only extracts that produced inhibition zone mentioned in the Table. Based upon inhibition index value obtained, root of $R$. apiculata (sample code 74) showed inhibition zone on agar media with gram positive bacteria $P$. acnes for all four solvents (74H, 74Ea, 74Et, and 74A) and extracts 74Ea and 74Et on media with $R$. equi. Sample 76Et also produced inhibition zone on agar media with $P$. acnes and $R$. equi bacterial strains.

Figure 2 showed an inhibition zone formed due to the addition of extract of root of B. gymnorrhiza (77Ea) on agar media with gram negative bacteria $E$. coli. The formed inhibition zone was the largest one with diameter $17.39 \mathrm{~mm}$ with inhibition index value of 1.8983 . Extracts $77 \mathrm{Ea}$ also produced inhibition zone as large as $7.89 \mathrm{~mm}$ in diameter on agar media with $P$. mosselii and $S$. aureus. Extracts $76 \mathrm{H}$, Ea and Et showed inhibition zone on agar media with $P$. acnes, $P$. mosselii and $R$. equi. The second highest inhibition index was 0.7867 recorded for leaf of water extract of $A$. $m a-$ rina (84 A) screened against $S$. aureus. Taken altogether, these data strongly suggested that mang- 
Table 4. Bacterial inhibition zone ( $\mathrm{mm})$ and inhibition index of extracts from different solvents*

\begin{tabular}{|c|c|c|c|c|c|c|}
\hline \multirow{2}{*}{ No. } & \multirow{2}{*}{ Sample code } & \multirow{2}{*}{$\begin{array}{l}\text { Bacterial } \\
\text { strains }\end{array}$} & \multicolumn{2}{|c|}{ Disk diameter + inhibiton zone $(\mathrm{mm})$} & \multicolumn{2}{|c|}{ Inhibition index } \\
\hline & & & Positive control & Samples & Positive control & Samples \\
\hline \multirow{2}{*}{1.} & \multirow{2}{*}{$\mathrm{RaL}(\mathrm{H})$} & P. acne & 15.95 & $7.54 \pm 0.76$ & 1.6583 & 0.2567 \\
\hline & & E. coli & 25.88 & $7.26 \pm 0.35$ & 3.1330 & 0.2100 \\
\hline 2. & Ral (A) & S. aureus & 17.32 & $7.11 \pm 0.25$ & 1.8875 & 0.1850 \\
\hline 3. & Ral (Et) & E. coli & 25.88 & $6.94 \pm 0.13$ & 3.3133 & 0.1567 \\
\hline 4. & $\mathrm{RaB}(\mathrm{H})$ & R. equi & 20.40 & $6.21 \pm 0.04$ & 2.4000 & 0.0350 \\
\hline 5. & $\mathrm{RaB}(\mathrm{Ea})$ & R. equi & 25.36 & $6.77 \pm 0.01$ & 3.2275 & 0.1275 \\
\hline 6. & $\mathrm{RaB}(\mathrm{Et})$ & P. acne & 25.66 & $6.50 \pm 0.02$ & 3.2767 & 0.0833 \\
\hline 7. & $\mathrm{RaB}(\mathrm{A})$ & P. acne & 25.66 & $6.99 \pm 0.40$ & 3.2767 & 0.1650 \\
\hline 8. & RaR (H) & P. acne & 15.95 & $6.17 \pm 0.06$ & 1.6583 & 0.0283 \\
\hline \multirow{2}{*}{9.} & \multirow{2}{*}{ RaR Ea } & P. acne & 11.25 & $6.29 \pm 0.06$ & 0.8750 & 0.0483 \\
\hline & & R. equi & 25.36 & $7.98 \pm 0.00$ & 3.2275 & 0.3300 \\
\hline \multirow{2}{*}{10.} & \multirow{2}{*}{$\mathrm{RaR}(\mathrm{Et})$} & P. acne & 28.74 & $6.87 \pm 0.14$ & 3.7892 & 0.1450 \\
\hline & & R. equi & 23.48 & $7.91 \pm 0.06$ & 2.9125 & 0.3183 \\
\hline 11. & RaR (A) & P. acne & 28.74 & $7.49 \pm 0.18$ & 3.7892 & 0.2483 \\
\hline 12. & BgL (Ea) & R. equi & 25.36 & $6.44 \pm 0.17$ & 3.2275 & 0.0733 \\
\hline 13. & BgL (A) & S. aureus & 16.90 & $6.43 \pm 0.16$ & 1.8175 & 0.0717 \\
\hline 14. & BgB (H) & P. acne & 12.49 & $6.90 \pm 0.24$ & 1.0817 & 0.1500 \\
\hline \multirow{2}{*}{15.} & \multirow{2}{*}{ BgB (Ea) } & P. acne & 17.88 & $6.89 \pm 0.15$ & 1.9800 & 0.1483 \\
\hline & & P. mosselii & 11.63 & $7.59 \pm 0.06$ & 0.9383 & 0.2650 \\
\hline \multirow{3}{*}{16.} & \multirow{3}{*}{$\mathrm{BgB}(\mathrm{Et})$} & P. acne & 23.32 & $7.30 \pm 0.21$ & 2.8858 & 0.2167 \\
\hline & & $R$. equi & 25.41 & $6.52 \pm 0.05$ & 3.2342 & 0.0867 \\
\hline & & S. aureus & 31.60 & $7.74 \pm 0.58$ & 4.2667 & 0.2900 \\
\hline \multirow[t]{2}{*}{17.} & \multirow[t]{2}{*}{ BgR (Ea) } & E. coli & 34.40 & $17.39 \pm 0.13$ & 4.7325 & 1.8983 \\
\hline & & P. mosselii & 11.63 & $7.89 \pm 0.06$ & 0.9383 & 0.3150 \\
\hline 18. & BgR (Et) & P. acne & 31.60 & $7.02 \pm 0.41$ & 4.2667 & 0.1700 \\
\hline \multirow{2}{*}{19.} & \multirow{2}{*}{$\operatorname{BgR}(\mathrm{A})$} & P. acne & 31.60 & $7.96 \pm 0.26$ & 4.2667 & 0.3267 \\
\hline & & E. coli & 34.40 & $7.71 \pm 1.23$ & 4.7325 & 0.2850 \\
\hline 20. & RmL (Ea) & R. equi & 20.81 & $6.48 \pm 0.35$ & 2.4683 & 0.0800 \\
\hline 21. & RmL (A) & S. aureus & 17.32 & $8.47 \pm 0.34$ & 1.8875 & 0.4117 \\
\hline 22. & $\mathrm{RmB}(\mathrm{H})$ & S. aureus & 30.31 & $6.79 \pm 0.22$ & 4.0517 & 0.1317 \\
\hline 23. & RmB (Ea) & R. equi & 20.81 & $7.25 \pm 0.01$ & 2.4683 & 0.2083 \\
\hline 24. & $\mathrm{TpR}(\mathrm{H})$ & R. equi & 21.80 & $6.68 \pm 0.07$ & 2.6325 & 0.1133 \\
\hline 25. & TpR (Ea) & P. mosselii & 11.88 & $6.25 \pm 0.01$ & 0.9792 & 0.0417 \\
\hline 26 & & P. acne & 11.85 & $6.91 \pm 0.23$ & 0.9750 & 0.1517 \\
\hline 26. & IpL (H) & R. equi & 21.80 & $7.13 \pm 0.01$ & 2.6325 & 0.1883 \\
\hline & & E. coli & 36.31 & $7.66 \pm 0.49$ & 5.0517 & 0.2767 \\
\hline 27. & $\mathrm{TpF}(\mathrm{H})$ & P. mosselii & 10.46 & $7.60 \pm 0.02$ & 0.7442 & 0.2667 \\
\hline & & R. equi & 21.80 & $6.92 \pm 0.07$ & 2.6325 & 0.1533 \\
\hline & & S. aureus & 27.50 & $6.59 \pm 0.33$ & 3.5825 & 0.0983 \\
\hline 28. & $\mathrm{~T} \mathrm{pF}(\mathrm{Ea})$ & E. coli & 36.31 & $6.85 \pm 0.47$ & 5.0517 & 0.1417 \\
\hline 29. & $\mathrm{TpF}(\mathrm{Et})$ & R. equi & 23.40 & $6.80 \pm 0.13$ & 2.8992 & 0.3000 \\
\hline & & P. acne & 11.85 & $6.87 \pm 0.14$ & 0.9750 & 0.1450 \\
\hline 30. & $A m L(H)$ & R. equi & 21.80 & $6.80 \pm 0.04$ & 2.6325 & 0.1333 \\
\hline 31. & AmL (A) & S. aureus & 16.90 & $10.72 \pm 0.72$ & 1.8175 & 0.7867 \\
\hline & & P. acne & 21.04 & $6.41 \pm 0.17$ & 2.5067 & 0.0683 \\
\hline 32. & $\operatorname{AmR}(\mathrm{H})$ & R. equi & 19.37 & $7.78 \pm 0.16$ & 2.2283 & 0.2967 \\
\hline 33. & XgL (H) & R. equi & 19.37 & $6.81 \pm 0.11$ & 2.2283 & 0.1350 \\
\hline 34. & CfL (H) & R. equi & 19.37 & $6.49 \pm 0.08$ & 2.2283 & 0.0817 \\
\hline 35. & ScL (H) & R. equi & 19.37 & $6.66 \pm 0.01$ & 2.2283 & 0.1100 \\
\hline 36. & ScL (Et) & P. acne & 24.78 & $8.39 \pm 0.24$ & 3.1292 & 0.3983 \\
\hline 37. & ScL (A) & P. acne & 24.78 & $7.58 \pm 0.04$ & 3.1292 & 0.2633 \\
\hline
\end{tabular}

Note: *Solvents abbreviation in parenthesis; $\mathrm{H}=n$-hexane, $\mathrm{Ea}=$ ethyl acetate, $\mathrm{Et}=$ ethanol, $\mathrm{A}=$ water. 
Table 5. Phytochemical qualitative analysis of mangrove extracts

\begin{tabular}{|c|c|c|c|c|c|c|c|c|c|}
\hline \multirow{2}{*}{$\begin{array}{l}\text { Sample } \\
\text { code }\end{array}$} & \multicolumn{3}{|c|}{ Alkaloid } & \multirow{2}{*}{ Triterpenoid } & \multirow{2}{*}{ Steroid } & \multirow{2}{*}{ Quinone } & \multirow{2}{*}{ Flavonoid } & \multirow{2}{*}{ Saponin } & \multirow{2}{*}{ Tannin } \\
\hline & Mayer & Wagner & Dragendof & & & & & & \\
\hline $\mathrm{RaL}$ & - & - & - & - & ++ & - & - & + & ++ \\
\hline $\mathrm{RaB}$ & - & - & - & + & - & - & - & +++ & ++ \\
\hline $\mathrm{RaR}$ & - & - & - & - & - & - & + & +++ & +++ \\
\hline $\mathrm{BgL}$ & - & - & - & - & ++ & - & +++ & +++ & +++ \\
\hline BgB & - & - & - & + & - & + & + & +++ & ++ \\
\hline BgR & - & - & - & - & - & - & - & +++ & +++ \\
\hline $\mathrm{RmL}$ & - & - & - & - & ++ & - & + & +++ & +++ \\
\hline $\mathrm{RmB}$ & - & - & - & - & - & + & - & +++ & +++ \\
\hline $\mathrm{TpR}$ & - & - & - & - & - & + & +++ & +++ & ++ \\
\hline $\mathrm{TpL}$ & - & - & - & - & +++ & - & - & +++ & + \\
\hline $\mathrm{TpF}$ & - & - & - & - & + & - & - & - & +++ \\
\hline $\mathrm{AmL}$ & - & - & - & - & + & - & ++ & ++ & ++ \\
\hline AmR & - & - & - & - & + & - & - & + & - \\
\hline XgL & - & - & - & - & + & - & - & +++ & + \\
\hline CtL & + & + & + & - & + & - & + & + & ++ \\
\hline ScL & - & - & - & - & + & - & ++ & - & +++ \\
\hline
\end{tabular}

Note:

-: absent; +: low amount; ++: considerable amount; +++: high amount as indicated by color intensity (data not shown)

rove extracts used in this study were potential as antibacterial agents with inhibition index value from the lowest to the highest were 0.0283 and 1.8983, respectively. Previous studies reported that mangrove extracts had shown their activity against microbes or pathogen parasites in animals and plants [7, 12] including HIV [13] and hepatitis-B virus [14].

\section{Phytochemical constituents}

Phytochemical qualitative analysis showed that most if not all extracts contain saponin and tannin in considerable amount (Table 5). The two phytochemical constituents and flavonoid had shown their activities against some bacteria [15]. Samples collected contained flavonoid and steroid in fewer amounts and no alkaloid detected in almost all samples.

Different colors shown in phytochemical analysis indicated that different species of mangroves as well as different parts of the plants contain different chemical constituents. It is important to note that chemical constituents and bioactivity of mangrove extracts and plants in general vary de- pend upon not only from species to species but also due to geographical conditions. This is also important to identify factors contributing to bioactivity, such as season, location and reproduction cycle stage [16]. Therefore, documentation of samples collection includes taxonomy, time and location, collector either individual or institution and species availability. This will be very helpful in tracing and sample monitoring during research process for accessibility purpose and benefit sharing and recollection.

The phenolic content, flavonoid content, and antioxidant activity of $R$. mucronata extract has been reported [17]. Considering the very large area covered by mangroves in Indonesia and worldwide, mangrove research, particularly for the purpose of drug discovery is still very limited. This opens up opportunities for researches to start putting their efforts individually and collaboratively on mangrove research which also applies to mangrove's associates.

\section{Conclusion}

In this study, different species and different 
parts of mangroves had been collected and had shown various phytochemical contents. Phytochemical contents found in mangroves strongly indicated that different species as well as different parts of the plants have different potentials as medicinal sources. There were 37 out of 64 extracts showed antibacterial potential with the lowest and the highest inhibition indexes were 0.0283 and 1.8983, respectively. The highest inhibition index was recorded for ethyl acetate extract of Bruguiera gymnorrhiza root (BgR (Ea)) against Escherichia coli. The second highest inhibition index was 0.7867 recorded water extract of Avicennia marina leaf (AmL (A)) against Staphylococcus aureus.

Further studies have to be conducted to elucidate potential compounds that possess bioactivity against tested bacteria or other microbial pathogens

\section{Acknowledgment}

Authors would like to thank the Ministry of Research, Technology and Higher Education, Republic of Indonesia for the research grant to Kholis Abdurachim Audah under contract Number: AGMT/Rec/A0018/III/2018. Authors thank the Swiss German University for financial support through the Central Research Fund and the Faculty Research Fund. Authors also like to thank the Biopharmaca Research Center, IPB University for allowing us to use their laboratory facilities.

\section{Reference}

1. World Health Organization Report. (1996).

2. Royal Botanical Garden Report 2016. (2017). State of the World's Plants.

3. Fauna Flora International Report. (2010).

4. Bandaranayake WM (2002) Bioactive compounds and chemicals constituents of mangrove plants. Wetland Ecology and Management 10: 421 - 452. doi: 10.1023/A:1021397624349.

5. Giri C, Ochieng E, Tieszen LL et al. (2011) Status and distribution of mangrove forests of the world using earth observation satellite data. Global Ecology and Biogeography 20 (1): 154 - 159. doi: 10.1111/j.1466-8238.2010.00584.x.

6. Mouafi FE, Abdel-Aziz SM, Bashir AA, Fyiad AA (2014). Phytochemical analysis and antibacterial activity of mangrove leaves (Avicenna marina and Rhizophora stylosa) against some pathogens. World Applied Sciences Journal 29 (4): 547 - 554. doi: 10.5829/idosi.wasj.2014.29.04.13901.

7. Audah KA, Amsyir J, Almasyhur, A M Hapsari and H Sutanto. (2018). Development of extract library from Indonesian biodiversity: exploration of antibacterial activity of mangrove Bruguiera cylindrica leaf extracts. IOP Conf. Ser.: Earth Environ. Sci. 130012025.

8. Association of Official Analytical Chemist [AOAC] (2006) Official methods of AOAC international $14^{\text {th }}$ Edition. Arlington (US), Association of Official Analytical Chemist.

9. Department of Health of the Republic of Indonesia (2009) Indonesian Herbal Pharmacopeia. First Edition. Jakarta (ID), Depkes RI.

10. Ravikumar S, Ali MS, Ramu A, Ferosekhan M (2011) Antibacterial activity of chosen mangrove plants against bacterial specified pathogens. World Applied Sciences Journal 14 (8): $1198-1202$.

11. Harborne JB (1987) Metode fitokimia. Padmawinata K, Soediro I, translator; Niksolihin S, editor. Bandung (ID), Bandung Institute of Technology. Translation from: Phytochemical Methods.

12. Batubara I, Mitsunaga T (2013). Use of Indonesian Medicinal Plant Products against Acne. Reviews in Agricultural Science 1: 11 - 30. doi: 10.7831/ras.1.11.

13. Rege AA, Chowdhary AS (2013) Evaluation of mangrove plants as putative Hiv-Protease inhibitors. Indian Drugs 50 (7): 41.

14. Yi XX, Deng JG, Gao CH et al. (2015) Four new cyclohexylideneacetonitrile derivatives from the hypocotyl of mangrove (Bruguiera gymnorrhiza). Molecules 20 (8): 14565 - 14575. doi: 10.3390/molecules200814565.

15. Murugan T, Wins JA, Murugan M (2013) Antimicrobial activity and phytochemical constituents of leaf extracts of Cassia auriculata. Indian Journal of Pharmacy 75 (1): 122 - 125. doi: 10.4103/0250-474X.113546.

16. Atanasov AG, Waltenberger B, Pferschy-Wenzig E et al. (2015) Discovery and resupply of pharmacologically active plant-derived natural products: A review. Biotechnology Advances 33 (8): 1582 - 1614. doi: 10.1016/j.biotechadv.2015.08.001

17. Audah KA, Manuella K, Amsyir J et al. (2018) Ultrasound-assisted extraction as efficient method for obtaining optimum antioxidant from mangrove leaves of Rhizophora mucronata. International Journal of Pharma and Bio Sciences (Special Issue): $47-55$. 
This page is intentionally left blank. 